\title{
AClR
}

Selected Papers of \#AolR2021:

The 22nd Annual Conference of the

Association of Internet Researchers

Virtual Event / 13-16 Oct 2021

\section{FACTS OF (FINANCIAL) LIFE: POLITICAL POWER AND RE- VISUALIZATION STRATEGIES ON SOCIAL MEDIA}

\author{
Eedan Amit-Danhi \\ Hebrew University
}

Digital political visualizations are a growing genre, providing an elegant solution to the informational overload that citizens encounter as they learn about the political world from social media. As visual representations of the numeric, scientific and seemingly impartial (Porter, 1996), the introduction of visualized political information and data is often viewed as a positive turning, away from personality politics and towards datacentered public debate (Naerland, 2020). However, when digital visualizations are used as part of political campaigns, they may also serve to misinform, persuade and divert attention (Amit-Danhi and Shifman, 2020). Thus, visualizations comprise a unique meeting point between political interests and the democratic greater good.

In political campaigns, candidates are engaged in a contest over the winning narrative. In a hybrid media world, political power, or the ability to "create, tap, or steer information flows in ways that suit their goals and in ways that modify, enable, or disable the agency of others" Chadwick, 2017: 285) may afford specific actors a head start in the race. Power manifests in different discursive and persuasive strategies. Powerful actors tend to focus on their persona (Rahat and Sheafer, 2007) through displays of emotionality, while peripheral actors tend to narrate reality through issue-oriented content (SamuelAzran et al., 2018). Demonstrated by widespread grassroots campaigns in the past decade, (e.g., \#metoo, BLM) the digital world offers a challenging, though somewhat effective pathway for awareness-raising.

In recent years, studies have explored the narrative, engagement and emotionality potentials of digital visualizations (see Kennedy et al, 2016; Weber, 2020; Kennedy and Hill, 2018). However, an analysis of the ways in which different actors utilize visualization for political persuasion and rhetoric has yet to emerge. Accordingly, I ask: "How do different types of political actors visualize the same political reality?"

\section{Method}

Suggested Citation (APA): Amit-Danhi, E. (2021, October). Facts of (financial) life: Political power and revisualization strategies on social media. Paper presented at AoIR 2021: The 22nd Annual Conference of the Association of Internet Researchers. Virtual Event: AolR. Retrieved from http://spir.aoir.org. 
Stemming from a failed budget approval process, Israel's 2015 election-cycle uniquely revolved around repeated refuting and confirming of financial facts. Using qualitative grounded analysis, I analyze a sample of all cost-of-living visualizations posted to Facebook by various political actors during the campaign period $(n=209)$, and contrast rhetorical strategies with the political power-stance of the posting actor.

\section{Findings}

Across the sample, different narrative, visual, and information-oriented strategies were applied by the actors in regards to Israeli cost-of-living. Analysis exposed two main visualization strategies: Progress Makers \& Hinderers and Re-visualized Economy.

In the category of Progress Makers \& Hinderers, visualizations tend to anoint and celebrate economic progress-makers, battle over credit, or assign blame (hindering). In this category, peripheral actors tended claim progress based on indisputable data such as parliamentary voting records in traditional scientific formats (see Fig.1), whereas primary actors visualized broad, uncited statements using simplified graphs (see Fig. 2). Several times throughout the election, the latter type of Progress-Maker visualizations were reposted by challenger-primary actors, overlaying their own narrative on top of the original claim (see Fig. 3).

Alternatively, in the category of Re-visualized Economy, peripheral actors' visualizations challenged existing perceptions of economic reality as part of an ongoing debate about the existence (or the extent) of an Israeli economic crisis. Two main strategies emerged: Humanizing Poverty, wherein visualizations emotionally contextualize economic data to define poverty in terms of its emotional and moral consequences (see Fig. 4); and Greener Grasses in which both peripheral and primary actors employ global comparisons of financial metrics to counteract the incumbent Prime Minister's claims about Israel's prospering economic state (see Fig. 5).

Despite their shared similarity in timeframe and subject, the visualizations in this sample took starkly different approaches, beginning with what was information chosen, as well as how it was visualized and for what rhetorical end. The visualization approached identified suggest rhetorical dynamics that correspond with political power structures, relating to three types of power: the powerful role of (visualized) numbers in political discourse, the persuasive power of emotions, and the political power of the actors posting the visualizations to social media. Across my findings, I highlight re-visualization an act of discursive and political resistance by weakened actors. Re-visualization is used by powerful actors in order to reclaim political narratives of achievements and failures (e.g., Fig. 3). Alternatively, when used by peripheral actors, re-visualization is applied in order to better their political stance in the battle of narratives. When they invite audiences to find the moral faults in the humanized reality of progress claimed by primary actors, or to be appalled at the wilting grasses of Israeli economy in comparison to its neighbors', they engage in acts of resistance (i.e. power-gaining) against primary narratives, by enlisting both the power of numbers, and the power of emotional persuasion.

\section{Conclusions}


This paper contributes a first in-depth exploration of visualization rhetoric as an expression of political power and a tool for resistance against it on social media. While studies have looked at political mechanisms of visualizations, the interplay depicted in this study provides much needed insight into the wide variety of strategies this growing genre provides political actors of all types for the dissemination of both benign and disinformative visualized messages on social media. Through the strategies defined and the political patterns detected, future studies may use this local study to explore the ways in which political actors utilize the power of visualization and revisualization throughout different political contexts.

\section{References}

Aiello G and Parry K (2020) Visual communication: Understanding images in media culture. SAGE Publications Limited.

Amit-Danhi ER and Shifman L (2018) Digital political infographics: A rhetorical palette of an emergent genre. New Media \& Society 20(10): 3540-3559.

Amit-Danhi ER and Shifman L (2020) Off the charts: user engagement enhancers in election infographics. Information, Communication \& Society: 1-19.

Chadwick A (2017) The hybrid media system: Politics and power. Oxford University Press.

Kennedy H, Hill RL, Aiello G and Allen W (2016) The work that visualisation conventions do. Information, Communication \& Society 19(6): 715-735.

Kennedy, H., \& Hill, R. L. (2018). The feeling of numbers: Emotions in everyday engagements with data and their visualisation. Sociology, 52(4), 830-848.

Nærland TU (2020) The political significance of data visualization: Four key perspective. In Engebretsen $\mathrm{M}$ and Kennedy $\mathrm{H}$ (eds) Data visualization in society. Amsterdam University Press, pp. 63-76.

Porter TM (1996) Trust in numbers: The pursuit of objectivity in science and public life. Princeton University Press.

Rahat G and Sheafer T (2007) The personalization (s) of politics: Israel, 1949-2003. Political communication 24(1): 65-80.

Samuel-Azran T, Yarchi M, and Wolfsfeld G (2018) Rhetoric Styles and Political Affiliations During Israel's 2013 "Facebook Elections". International Journal of Politics, Culture, and Society 31(1): 15-30.

Towner TL (2017) The infographic election: The role of visual content on social media in the 2016 presidential campaign. In Schill D and Hendricks JA (eds) The presidency and social media. Routledge: pp. 236-262. 
Weber W (2020) Exploring narrativity in data visualization in journalism. In Engebretsen $\mathrm{M}$ and Kennedy $\mathrm{H}$ (eds) Data visualization in society. Amsterdam: Amsterdam University Press, pp. 295-312.

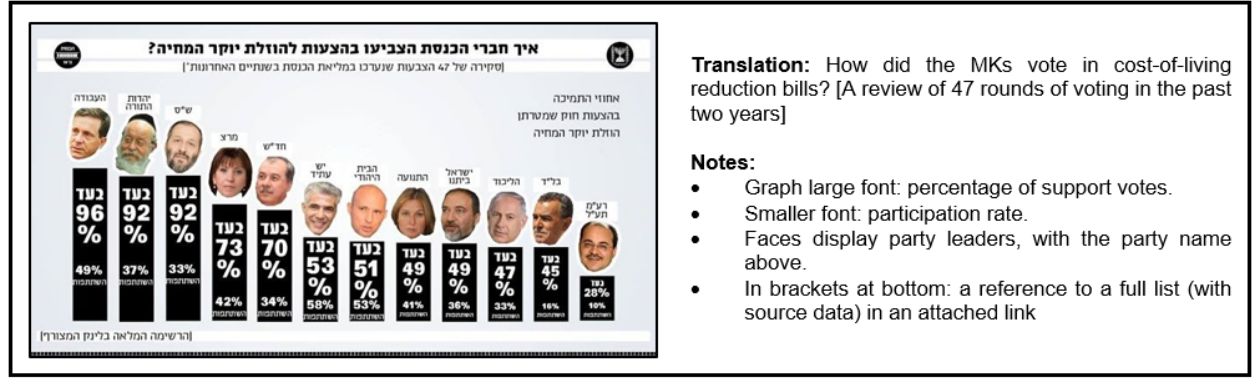

Fig. 1: How did they vote? February 22, 2015.

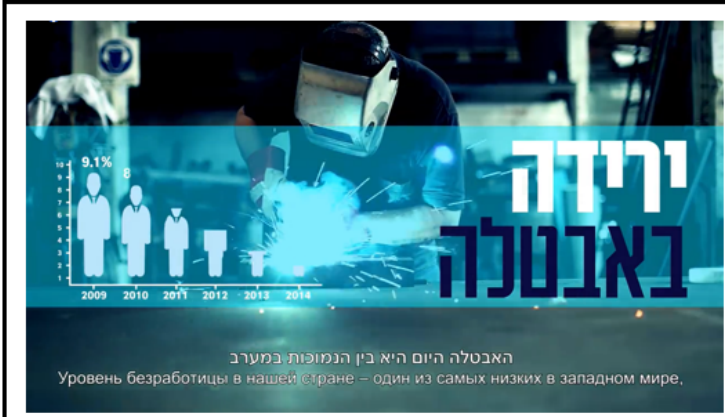

Translation: Lowered unemployment

[subtitles] Unemployment today is of the lowest in the Western World

Fig. 2: Netanyahu. March 5, 2015.

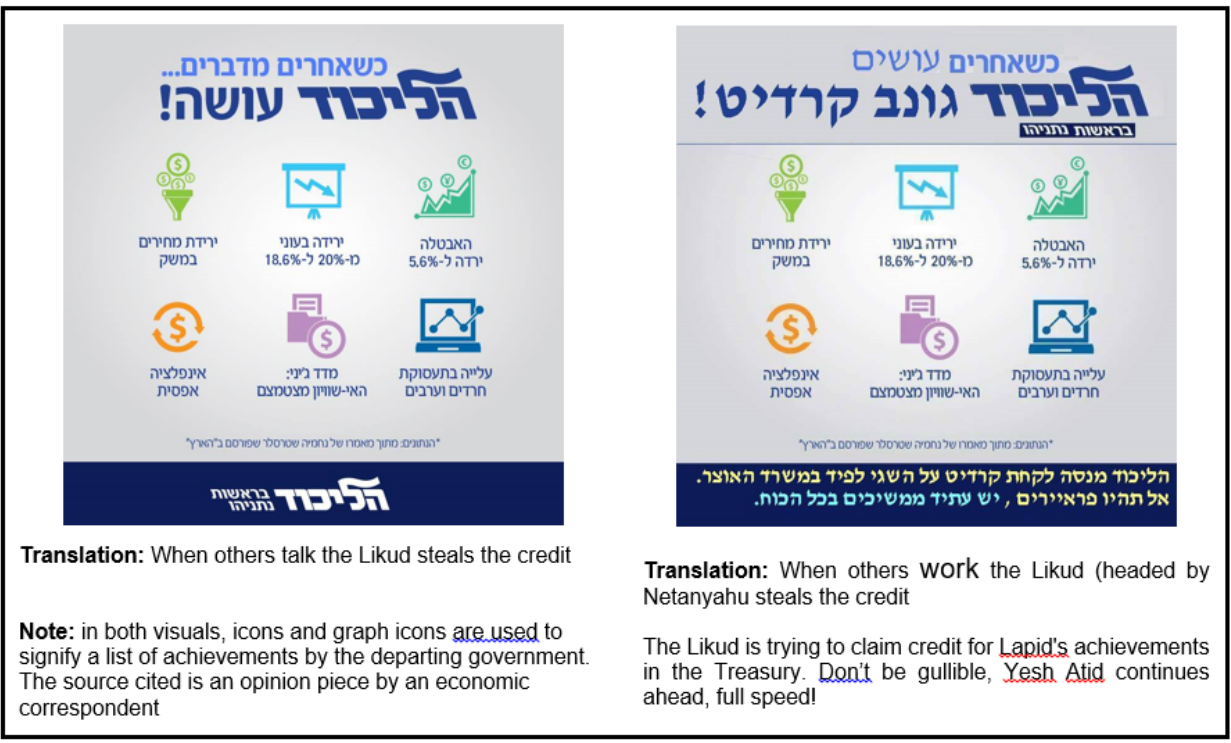

Fig. 3: Revisualized Progress Making. Netanyahu (right) and Gadi Meiri (Left), January 20 and 30, 2015. 


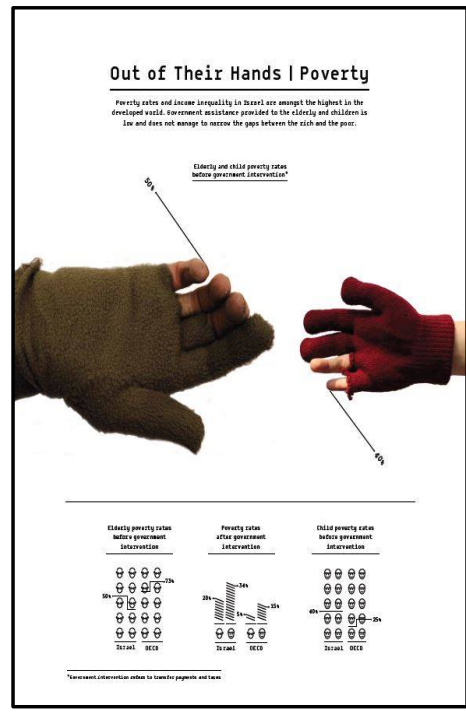

Fig. 4: Taub Center, February 1, 2015.

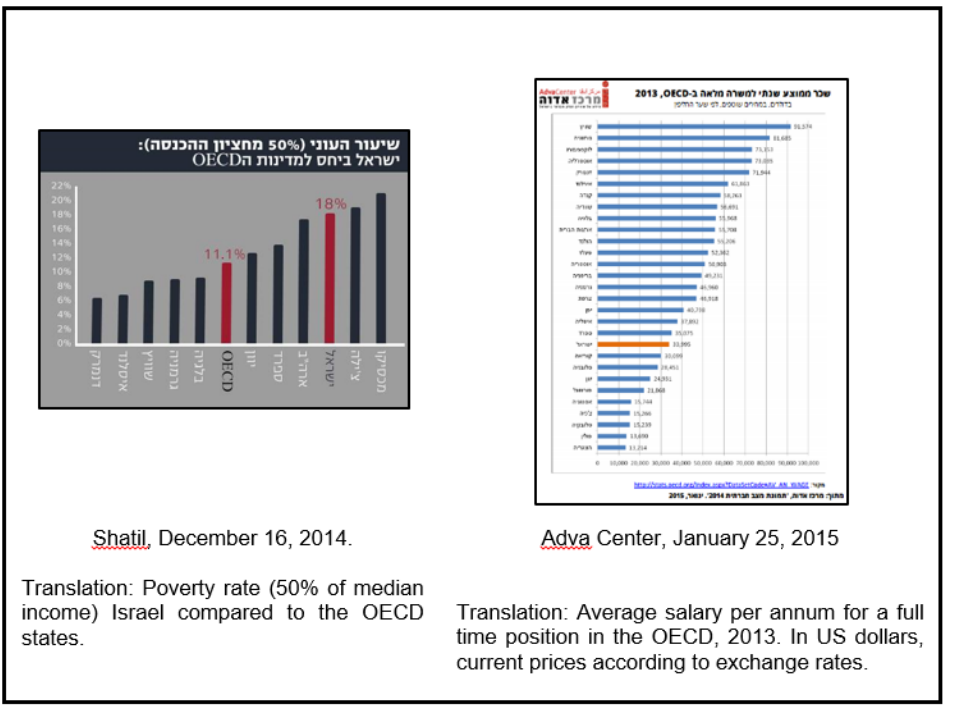

Fig. 5: Greener grasses - comparing Israel to its OECD peers. 